\title{
Pigmentary Mosaicism with Myxomatous Mitral Valve Disease and Various Extra Cutaneous Findings
}

\author{
Akshit Chitkara $^{1^{*}}$ and Shikhar Ganjoo ${ }^{2}$ \\ ${ }^{1}$ Intern SGT Medical College, Hospital and Research Institute, Gurgaon, India \\ ${ }^{2}$ Department of Dermatology, Hospital and Research Institute, SGT Medical College, Gurgaon, India
}

"Corresponding Author: Akshit Chitkara, Intern SGT Medical College, Hospital and Research Institute, Gurgaon, India, Tel: 9996906642; E-mail: akshit.chitkara6@gmail.com

Received date: July 04, 2018; Accepted date: July 30, 2018; Published date: August 06, 2018

Copyright: (c) 2018 Chitkara A, et al. This is an open-access article distributed under the terms of the Creative Commons Attribution License, which permits unrestricted use, distribution, and reproduction in any medium, provided the original author and source are credited.

\begin{abstract}
Pigmentary mosaicism is a very rare disorder characterized by unilateral or bilateral mosaicism. There are patterned hypo pigmented and hyper pigmented whorls, streaks and patches corresponding to the lines of blaschko. Both hypopigmented and hyper pigmented streaks may coexist in the same individual. We describe a patient of Pigmentary mosaicism with myxomatous mitral valve disease and multiple extra cutaneous findings.
\end{abstract}

Keywords: Pigmentary mosaicism; Infantile spasms; Myxomatous mitral valve disease; Clinodactyly; Campylodactyly; Bat ears; Umbilical hernia

\section{Introduction}

The term pigmentary mosaicism is preferred for this heterogeneous group of disorders that includes hypomelanosis of Ito (incontinetia pigmenti achromians), linear and whorled nevoid hypermelanosis and the segmental form of nevus depigmentosus [1,2]. It is characterized by patterened streaks of dyspigmented lesions along the lines of blaschko, phylloid, checker board pattern and patchy pigmentation.

It is particularly caused by chromosomal mosaicism and it is highly varied in its phenotype with extracutaneous anomalies in $75 \%$ of cases. This case describes various cutaneous, extracutaneous and cardiac anomalies associated with pigmentary mosaicism.

\section{Capsule summary}

Pigmentary mosaicism encompasses group of disorders that include hypomelanosis of Ito, linear and whorled nevoid hypermelanosis and the segmental form of nevus depigmentosus [2-4]. We describe various musculoskeletal and cardiac anomalies with pigmentary mosaicism. It will guide physicians to look for cardiac anomalies in pigmentary mosaicism cases and provide timely intervention.

\section{Case Report}

An 8-year-old, female child presented to our department of pediatrics with chronic cough, delayed developmental milestones and learning difficulties. She was a child born out of a non-consanguineous marriage at term gestation. Post-natal history included complaints of myoclonic jerks for which no consultation was sought. Family history is not suggestive of any linkage. Also the child had a history of gastro esophageal reflux. No history of breathlessness, cyanosis or wheezing.

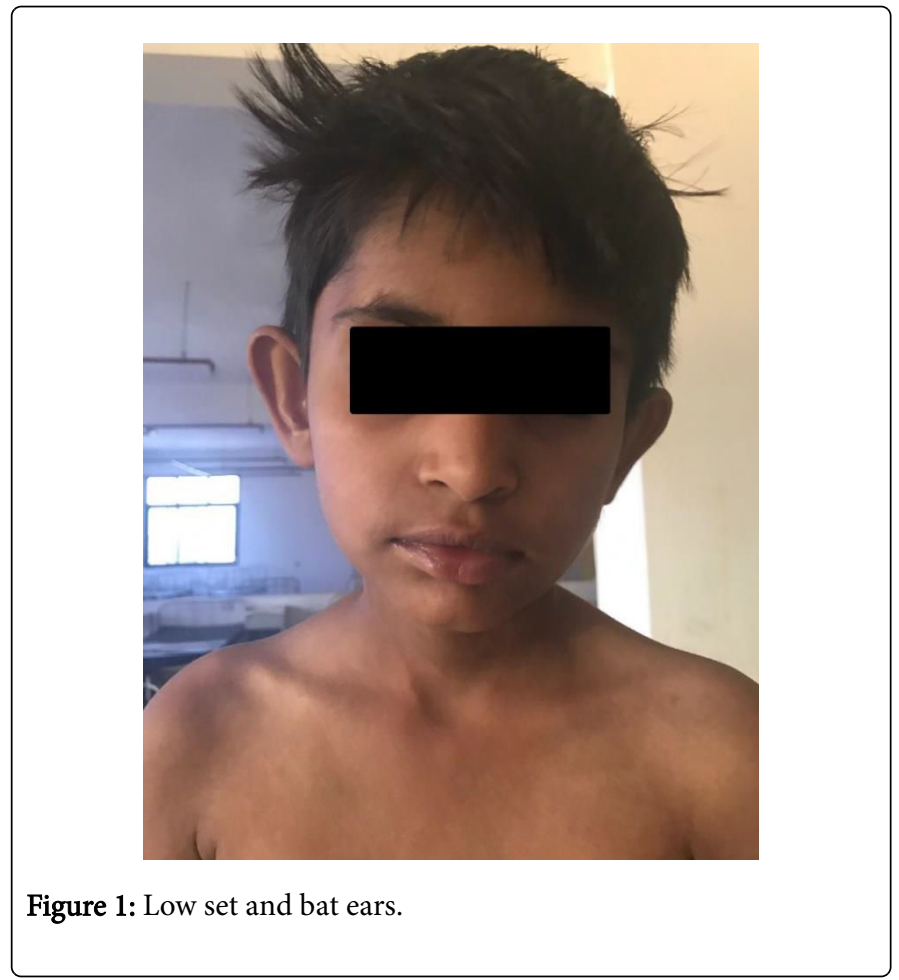

On musculoskeletal examination there was an asymmetry of limbs and various parts of body. Child had kyphoscoliosis, low set and bat ears (Figure 1), widely spaced nipples and at different levels (Figure 2a). There was camptodactyly and Clinodactyly (Figure $2 \mathrm{~b}$ ) present in little finger of both the hands. The child had umbilical hernia (Figure 3). Cutaneous examination showed streaks of hyperpigmentation present on chest, abdomen (Figure 4), back (Figure 5), buttocks (Figure 6a), both flexor and extensor aspect of arms and legs (Figure 6b) along the lines of blaschko. On cardiac examination, the child had no murmurs and no positive findings on auscultation. 
Citation: Chitkara A, Ganjoo S (2018) Pigmentary Mosaicism with Myxomatous Mitral Valve Disease and Various Extra Cutaneous Findings. J

Page 2 of 3

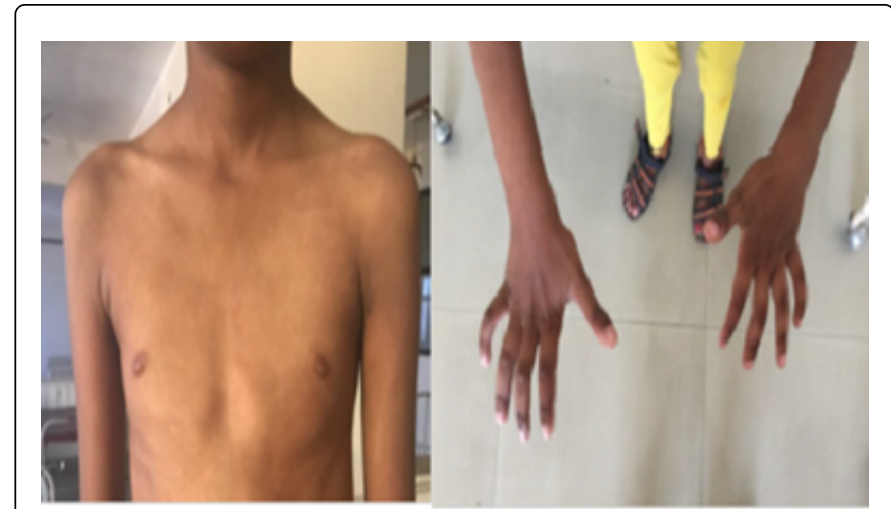

2a

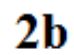

Figures 2: The Figure (2a) indicates widely spaced nipples and Figure (2b) indicates Clinodactyly and campylodactyly.

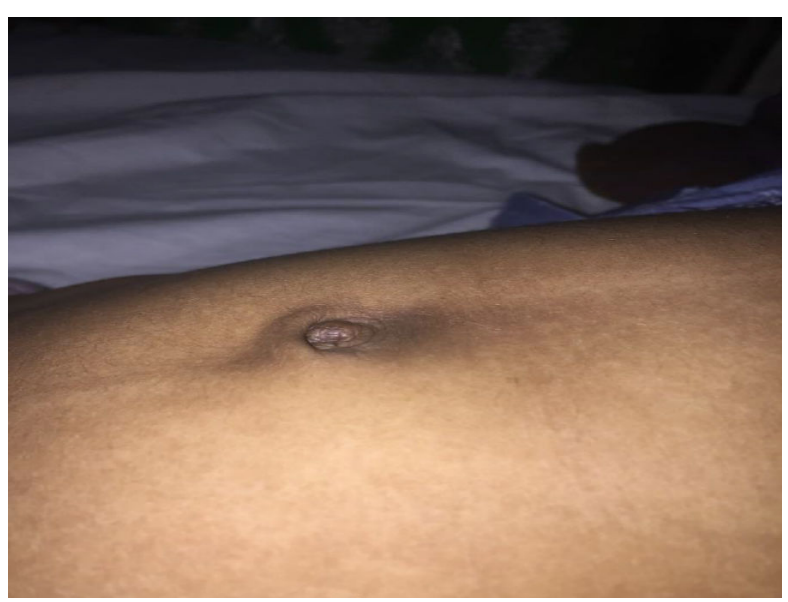

Figure 3: Umblical hernia.

Routine hematological investigations and serum biochemistry profile were within normal limits. Thyroid function tests showed normal T3, T4 and TSH. MRI of brain and ultrasound abdomen was normal. CBNAAT was negative for tuberculosis. X-ray chest was done for chronic cough but there were no abnormal findings in lungs. It had increased cardiothoracic ratio and a boot shaped heart for which echocardiography was done. Echocardiography showed myxomatous valves and an ejection fraction of $60 \%$ (Figures $7 \mathrm{a}$ and $7 \mathrm{~b}$ ). Due to lack of facilities fibroblast culture from the skin biopsy could not be done. On the basis of clinical and radiological findings, a diagnosis of pigmentary mosaicism with skeletal abnormalities (camptodactyly and clinodactyly) and myxomatous mitral valve disease was made.

\section{Discussion}

The condition described Pigmentary mosaicism is a very rare disorder characterized by unilateral or bilateral mosaicism. There are patterned hypo pigmented and hyper pigmented whorls, streaks and patches corresponding to the lines of blaschko. It is particularly caused by chromosomal mosaicism and it is highly varied in its phenotype with extracutaneous anomalies in $75 \%$ of cases. Gene mosaicism of a locus is the underlying basis of pigmentary mosaicism. Familial linkage is rare in these cases. Around $60 \%$ of paediatric cases with widespread pigmentary mosaicism are found to have gross chromosomal abnormalities and/or noncutaneous abnormalities on peripheral blood leukocyte and fibroblast or keratinocyte evaluation. However majority cases do not show extensive involvement with pigmentary mosaicism and have no other problems on taking history along examination. These cases may not be investigated further but early diagnosis and intervention can drastically improve the prognosis of the disease.

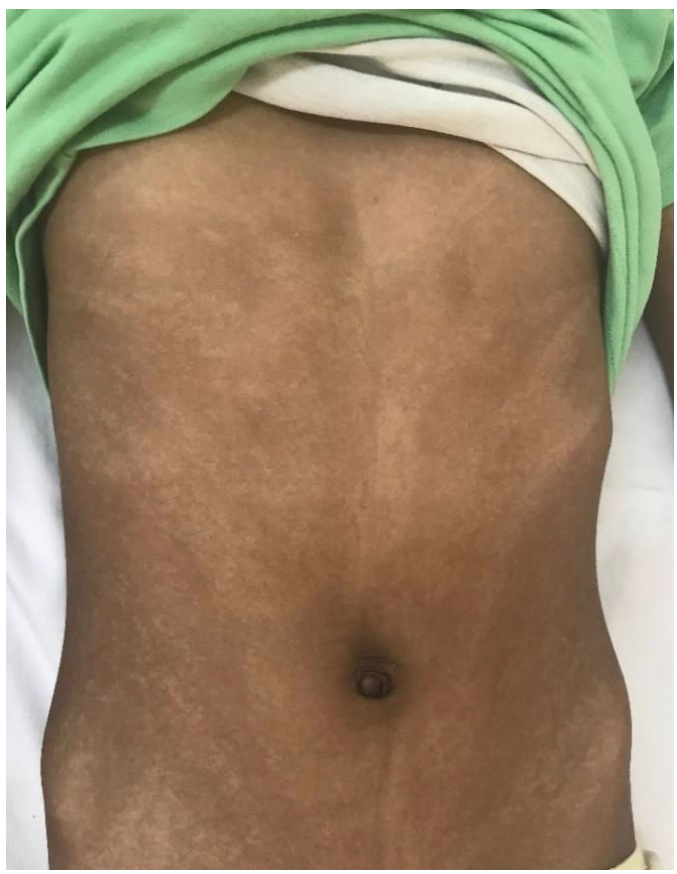

Figure 4: Streaks along the lines of blaschko on the trunk.

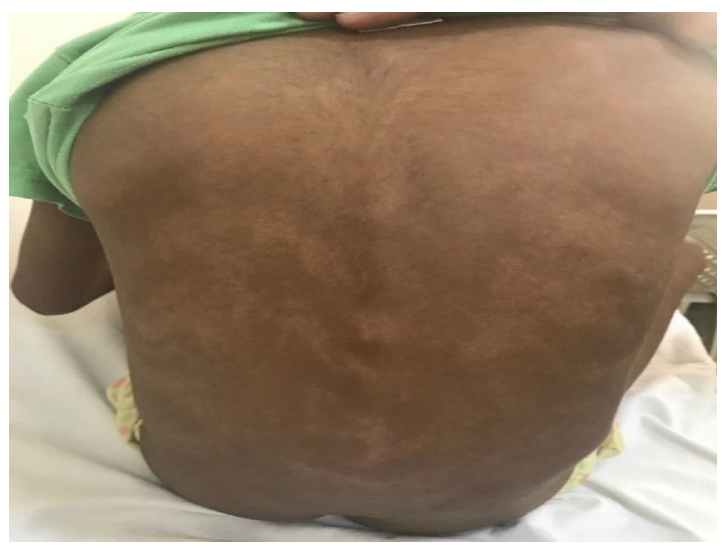

Figure 5: Back. 
Citation: Chitkara A, Ganjoo S (2018) Pigmentary Mosaicism with Myxomatous Mitral Valve Disease and Various Extra Cutaneous Findings. J Cosmo Trichol 4: 1000136. doi:10.4172/2471-9323.1000136

Page 3 of 3

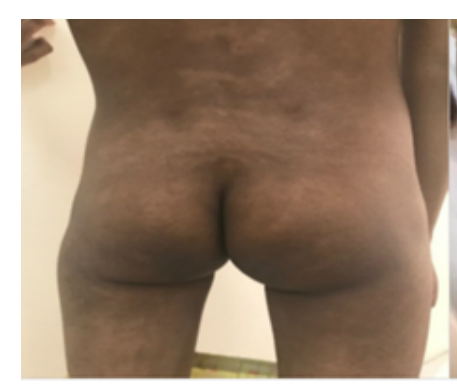

6a

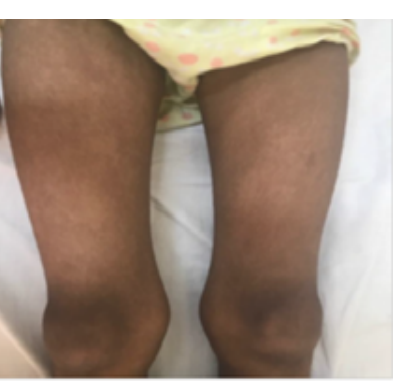

6b
Figures 6: The Figure (6a) indicates Buttocks and Figure (6b) indicates Lower limbs.

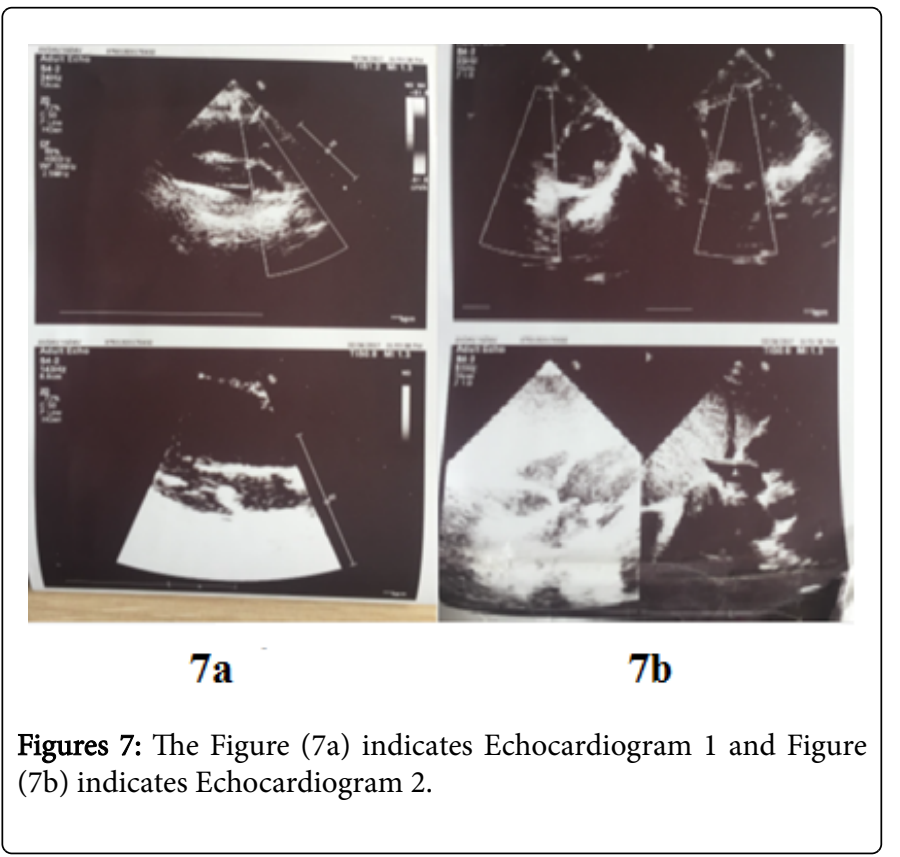

\section{Reference}

1. Christopher Griffiths, Jonathan Barker, Tanya Bleiker, Robert Chalmers, Daniel Creamer Alain Taieb, et al. (2016) Hypomelanosis of Ito In: editors. Rook's Textbook of Dermatology 9th ed. Wiley Blackwell Publishing.

2. Hurwitz Clinical paediatric dermatology 5 th ed.

3. Daniel Bernstein-Mitral Valve Prolapse In: Nelson Textbook of pediatrics 1st south Asia edition Volume 2: $\mathrm{p} 2210$.

4. Happle R (2010) The group of epidermal nevus syndromes. Part I Well defined phenotypes. J Am Acad Dermatol 63: 1-22. 